\title{
Inter-generational Linkages of AIDS: Vulnerability of Orphaned Children for HIV Infection
}

\author{
Lucie Cluver and Don Operario
}

\begin{abstract}
1 Introduction
As the number of deaths associated with AIDS increases, especially in the developing world, addressing the health and wellbeing of children affected by AIDS becomes ever more important. Much has been debated about the inter-generational impact of AIDS and the vulnerabilities among orphaned children, but evidence to resolve these debates has remained limited and existing studies have not been synthesised in a coherent manner. A concern among public health scientists and policymakers is whether children orphaned in the context of HIV/AIDS are at heightened risk for becoming infected with HIV - not through vertical transmission, but through sexual behaviours or exposure to infectious bodily fluids. This article examines the evidence on this issue, focusing attention on three subgroups of children who might experience inter-generational consequences of AIDS: (1) children orphaned by AIDS, (2) children with caregivers who are living with HIV, and (3) children in families affected by HIV/AIDS. This final group has a range of definitions, but refers here to children who either live in a household with person(s) infected by HIV, or who have immediate family members (whether co-resident or not) who are infected with HIV. Heightened associations between orphanhood and risk for HIV infection would necessitate a call for improved linkages between social care and HIV prevention programmes for children orphaned by AIDS or other children vulnerable to familial HIV/AIDS.
\end{abstract}

\section{Preliminary evidence on increased risk for HIV infection for orphaned children}

We have not been able to identify any study which explicitly explores the causative links between familial
HIV infection, AIDS-orphanhood and orphaned children's subsequent risk of HIV infection.

Preliminary evidence for this pathway has been established by a small number of cross-sectional studies of associations between orphanhood (though not distinguishing AIDS-orphanhood from otherorphanhood) and risk for HIV infection.

Evidence for higher prevalence of HIV status among orphans derives from four known studies. $A$ population survey of 15-18-year-old children in Zimbabue (Gregson et al. 2005) found female orphans significantly more likely than non-orphans to be HIV-positive, and to have experienced symptoms of sexually transmitted infections (STIs) and pregnancy, controlling for sociodemographic co-factors. Male orphans in this study did not show higher rates of HIV or symptoms of STI. A follow-up study of 1,283 15-19-year-old girls in Zimbabwe (Birdthistle et al. 2008), found orphan status among girls who had never been married was significantly associated with testing positive for HIV infection, having herpes simplex virus-2, and a history of pregnancy. A national representative household survey of young people aged 15-24 in South Africa (Operario et al. 2007) found female orphans were more likely than nonorphans to test HIV-positive, controlling for socioeconomic co-factors; however, although male orphans were more likely to test HIV-positive than non-orphans overall, this association was not significant when controlling for socioeconomic cofactors. A study (Kissin et al. 2007) of street youth aged 15-19 in St Petersburg, Russia, found double orphans were 3.3 times and single orphans 1.8 times more likely than non-orphans to be HIV-positive. 
Further evidence shows higher rates of sexual behaviour among orphaned children. A study of South African children aged 14-18 found orphans were more likely to have ever had sex than non-orphans and, among those sexually active, orphans experienced an earlier sexual debut (Thurman et al. 2006). A national survey of children aged $12-17$ in Zimbabwe found paternal and maternal single orphans, but not double orphans, were more likely than non-orphaned, non-vulnerable children to have had sex, but they were not more likely to report having had 'high risk' sex (Nyamukapa et al. 2008). By contrast, in the national household survey of South African young people (Operario et al. 2007), female orphans were more likely than non-orphans to have ever had oral and vaginal sex as well as multiple sex partners during the past year, and male orphans were more likely than non-orphans to have ever had vaginal sex and unprotected sex at last sexual episode. $A$ study of 1,200 children aged 10-17 in Nyaza Province, Kenya (Juma et al. 2007), found orphans were more likely than non-orphans to have had sex, and that female maternal orphans were more likely to have had sex than girls whose mothers were alive. Among children who had had sex, the mean age of first sex was younger for girl orphans than girl non-orphans. There were no differences in the mean number of sexual partners. Orphaned boys were more likely than non-orphaned boys to report first sex with a stranger. Orphans reported significantly lower condom use at last sex than non-orphans.

Two reviews of the Demographic and Household Survey (DHS) data suggest earlier sexual debut among orphaned than non-orphaned children in sub-Saharan Africa. Campbell et al. (2008) analysed data on 15-17-year-old orphans from Lesotho, Malawi, Mozambique, Rwanda and Tanzania. Double orphans were more likely than other groups (maternal, paternal orphans and non-orphans) to have experienced sexual debut, especially in urban areas. $\mathrm{A}$ review of DHS data from eight countries in south and east Africa (Chad, Congo, Lesotho, Malawi, Mozambique, Tanzania, Uganda and Zimbabwe) (Palermo and Peterman 2008) found no association between orphanhood and early marriage. Orphan status was significantly associated with early sexual debut in Lesotho, Mozambique, Tanzania and Uganda.

Although these data are suggestive of an elevated risk for HIV and sexual risk among some orphan populations, there are important limitations. First, it is important to note the paucity of empirical findings on HIV and sexual risk among orphans; the number of known studies remains inadequate given the severity of this issue. Second, all known studies examined cross-sectional datasets, and could not establish whether orphanhood preceded onset of HIV-risk behaviours. Third, these studies compared general orphaned versus non-orphaned youth, and could not specify inter-generational impacts of parental AIDS-related deaths on surviving children's health and wellbeing.

\section{Hypothesised pathways by which AIDS orphanhood affects HIV risk}

Based on our review of the literature, we have identified five potential pathways or mechanisms by which being an AIDS-orphaned child can increase risk for HIV infection:

- Poverty among AIDS-orphaned and other orphaned children

- Mental health problems among AIDS-orphaned and other orphaned children

- Characteristics and dynamics of sexual behaviour among AIDS-orphaned and other orphaned children

- Caregiving stressors and family violence among AIDS-orphaned and other children

- Sexual abuse and victimisation experienced by AIDS-orphaned and other children.

Each potential pathway will be considered below. The evidence on each is limited, and additional research is necessary in order to verify or refute these hypotheses. It is likely that HIV risk is determined by multiple co-occurring factors, which may operate simultaneously and at different levels of analysis (individual, family, community), rather than through one predominant factor.

\section{Poverty and HIV risk}

There is strong evidence of increased poverty among families affected by AIDS (Gillespie, this IDS Bulletin) and among families caring for orphans (Case et al. 2002). A direct causal effect of poverty on HIV infection has been contested, as data show that the poorest are rarely those with highest HIV prevalence (Gillespie, this IDS Bulletin). Despite this, there are compelling hypothesised pathways by which poverty contributes to HIV risk. 


\subsection{Caring for AIDS-affected family members}

Care for AIDS-unwell family members frequently takes place in the home, and may be provided by children (Bauman et al. 2006). This practice can expose childcarers to diarrhoea, blood and skin lesions, which are potentially infectious (although with small associated risk). We were unable to identify any quantitative studies examining the prevalence of children who serve as primary caregivers for AIDS-unwell parents. However, given the paucity of health professionals in the developing world, children (especially daughters) are likely candidates for providing care for AIDSaffected adults (Nostlinger et al. 2006). Risk of HIV infection to carers of AIDS patients is very low when adequate protection is used, particularly gloves (Wood et al. 1997).

However, qualitative evidence reports that some carers are unable or unwilling to use protective materials while caring (Lindsey et al. 2003). There is also anecdotal evidence of inadequate supplies of protective materials to home-based carers, especially in rural areas (Nsutebu et al. 2001).

\subsection{Reduced access to healthcare}

There is some evidence of reduced access to medical treatment among orphans. DHS survey data in Kenya shows orphans are more likely to have untreated acute respiratory infections (ARI) (Mishra et al. 2005), and qualitative data reports discrimination in healthcare access for children in HIV-affected families (Giese et al. 2003). Research suggests that lack of access to appropriate healthcare may lead to higher likelihood of untreated STIs, and thus increased susceptibility to HIV infection (Fleming and Wasserheit 1999).

\subsection{Reduced access to education}

HIV risk has been shown to be related to low school access or attainment (Bärnighausen et al. 2007). There is increasing evidence from the developing world, and particularly from sub-Saharan Africa, that children in HIV-affected families and orphaned children experience reduced enrolment, reduced school attendance and higher rates of school dropout (Case and Ardington 2005; Operario et al. 2008; Campbell et al. 2008). Qualitative studies suggest that, where children in AIDS-affected families are not attending school, girls are more likely to be removed from school to perform caring roles, while boys are more likely to seek employment to assist the household (Steinberg et al. 2002).

\section{Mental health problems and HIV risk}

A review of 23 studies in 2007, and earlier reviews, have established strong associations between AIDSorphanhood and increased mental health problems in both the developed and developing world (Wild 2001; Cluver and Gardner 2007). There is also increasing evidence of mental health problems for children of HIV-positive parents (Forehand et al. 1998; Esposito et al. 1999; Su et al. 2007). Outside the USA, there is little evidence for substantially increased behavioural problems among AIDSaffected children (Cluver et al. 2007).

However, in both the developing and developed world there is increasing evidence of internalising problems (Atwine et al. 2005) and post-traumatic stress (Cluver et al. 2007). These may impact on HIV risk in different ways. $A$ recent study in Zimbabue found higher sexual HIV-risk behaviours among orphaned adolescents, which was reduced when controlling for psychological distress (Nyamukapa et al. 2008)

\subsection{Clinical-level mental health problems}

A review of 66 studies indicated that adolescents with psychiatric disorders (largely in US studies) are at greater risk of HIV infection (Brown et al. 1997). One study of 1,050 adolescents in South Africa which used validated psychological tools found that AIDSorphaned children had clinical-level disorders at rates well above other orphans, non-orphans and Western norms (Cluver et al. 2007).

\subsection{Internalising problems}

Internalising problems are often called 'emotional problems', and indicate internal manifestation of psychological distress (e.g. depression and anxiety) rather than acting them out in the environment (e.g. behaviour problems, conduct problems). There is evidence that children living with HIV-positive caregivers, or orphaned by AIDS, are at higher risk for internalising problems than other children (i.e. Makame et al. 2002; Bhargava 2005). But there is little direct evidence of associations between depression, anxiety and HIV risk among adolescents.

\subsection{Use of alcohol and substance use}

There is clear evidence of increased sexual risk behaviour associated with the use of alcohol and substances such as mandrax and methamphetamine (Dahoma et al. 2006). A recent meta-analysis of African studies shows alcohol use to be associated 
with HIV infection, but these are largely in adult populations (Fisher et al. 2007). There is evidence from sub-Saharan Africa of a link between alcohol and risky sex for youth (Campbell 2003), and as a particular risk for concurrent sexual partnerships (Parker et al. 2007). Whether orphaned children use drugs and alcohol more than non-orphaned children remains unknown. We were only able to identify one study in Africa directly examining alcohol or substance use among orphaned children or children in families affected by AIDS. In Kenya, orphaned children, especially maternal orphans, reported more alcohol use and attendance of night activities (Juma et al. 2007).

\section{Dynamics of sexual behaviour and HIV risk}

Is it possible that AIDS-affected children are showing different kinds of sexual risk behaviour than other youth? The South African national survey of HIV risk (Operario et al. 2007) found that female orphans had a higher likelihood of being HIV-positive, of having ever had sex, and of higher rates of sexual

concurrency (defined as more than one sex partner during the last year), but not a higher likelihood of unprotected sex. We were not able to identify any study which specifically explores the partnerships and sexual risks of children in families affected by AIDS.

\subsection{Concurrent sexual partnerships}

Recent evidence has highlighted the importance of concurrent sexual partnerships in the transmission of HIV. Qualitative data suggest a number of social drivers of concurrency, including factors which may be relevant to orphanhood, such as the need for 'spare' partners in order to reduce fears of rejection or of being alone (Parker et al. 2007), and concurrent partners as an economic strategy or necessity. There are no known studies directly investigating these associations.

\subsection{Transactional sex}

'Transactional sex' is here defined as the exchange of sex for food, education or other material gain. It is often also associated with concurrent sexual partnerships. There is evidence that engagement in transactional sex increases the risk of HIV infection, due to the limited capacity to negotiate safe sex and increased levels of partner coercion and violence (Dunkle et al. 2004). A study involving South African orphans reported higher likelihood of engaging in transactional sex (Thurman et al. 2006), even controlling for poverty.

\subsection{Older sexual partners, sugar daddies and sugar mummies}

Qualitative evidence suggests that poor children or orphaned children may engage in a relationship with an older partner (often called a 'sugar daddy' or 'sugar mummy') to fund school or other expenses (Muula et al. 2003; Oleke et al. 2007). Such a pattern of gift-giving and financial support can encourage lower condom use (Jewkes et al. 2001). Increasing evidence shows that sexual relationships with older men are driving the disproportionate HIV prevalence among adolescent girls in South Africa (Pettifor et al. 2003). A study in Kenya reported that orphaned children sought out older partners in order to replace a parental figure, or to provide them with emotional support, affection and attention which was lacking in foster homes (Longfield et al. 2004). A qualitative study in Botswana among young girls with sugar daddies shows associated limitations on the girls' capacity to negotiate safe sex (Nkosana and Rosenthal 2007).

\subsection{Sex at a younger age}

Quantitative large-scale evidence from South Africa and Zimbabue shows orphaned children to be more likely to have had sex at a younger age than nonorphans (Gregson et al. 2005; Thurman et al. 2006). Earlier onset of sexual activity is associated with having more sexual partners, lower condom use, and increased likelihood of contracting HIV and other STIs (Pettifor et al. 2004). Some studies suggest that early sexual debut among girls is associated with heightened susceptibility to infection due to immaturity of the female genital tract and cervical ectopy, which is common among young women (Royce et al. 1997).

\section{Caregiving stressors, family violence and HIV risk}

Hypotheses between caregiving stress and family violence as determinants of HIV risk for orphaned children are tentative, owing to little empirical research. However, there are indications that orphaned children are indeed affected by caregiving stress and family violence, which may increase their chances of engaging in risky sexual behaviour.

\subsection{Reduced parental monitoring}

Among orphans in sub-Saharan Africa, several studies suggest that caregiver monitoring is negatively associated with general (non-sexual) behaviour problems (Nyamukapa et al. 2006; Wild et al. 2006). Child-headed households lack consistently present 
adult caregivers, and HIV-positive carers may be unable to supervise children due to sickness or HIVassociated depression (Rochat et al. 2006; Brandt 2007). Grandparent caregivers and heads of childheaded households report high levels of anxiety and depression (Ferreira et al. 2001; Manuel 2002; Boris et al. 2006). A study in Kenya found that orphans reported less supervision by adults at home, and perceived that they were less loved at home than non-orphans (Juma et al. 2007).

\subsection{Domestic violence in households with HIV}

We were unable to identify any reliable data in subSaharan Africa regarding prevalence of domestic violence among orphan samples. However, studies in South Africa have shown heightened levels of domestic violence in AIDS-affected families (Jewkes et al. 2003). Data from the developed world suggests a link between childhood experience or witnessing of domestic violence and later risky sexual behaviour (Albus et al. 2004).

\subsection{Physical abuse of children}

There are no known reliable data on exposure to physical abuse of children in families affected by AIDS (Dawes et al. 2006). Qualitative studies in Kenya and South Africa report increased experience of physical abuse among orphans (McGaw and Wameyo 2005). As with all forms of abuse, experience of physical violence increases risk of child emotional and behavioural problems, and may increase risk of dating violence in adolescence (Rowan and Foy 1993; Deblinger et al. 1996).

\section{Sexual abuse, rape and HIV risk}

All evidence regarding sexual abuse and rape are limited by inadequate reporting and recording. Prevalence data for child sexual abuse in the developing world are particularly unreliable (Dawes and Mushwana 2007). We were unable to identify any quantitative studies which specifically examine associations between abuse and living in a family affected by AIDS. A national survey of 16-24-yearolds in South Africa found no associations between forced sex and orphanhood (Operario et al. 2007).

\subsection{Sexual abuse in the home}

Anecdotal reports have suggested that some orphaned children, particularly in foster homes, might experience sexual abuse. However, no quantitative studies were identified which allow comparison of abuse rates with other groups of children.

\subsection{Living on the streets and sexual abuse}

There is anecdotal evidence from staff of street-child projects to suggest an increasing trend of AIDSorphaned children living on the streets. However, there is no reliable quantitative data in sub-Saharan Africa regarding proportions of AIDS-orphaned and AIDS-affected children who become street children.

\section{Conclusions}

Based on a comprehensive review of published and unpublished literature on the inter-generational impacts of HIV, the report finds some initial evidence that orphaned children may be at a heightened risk for HIV infection compared with non-orphaned children. Evidence more clearly suggests that orphaned children and children in AIDS-affected families might experience greater psychosocial distress and educational shortfalls compared with control groups, which usually consist of nonorphaned children. These findings merit both scientific and policy attention, which demand appropriate levels of support and funding to address existing gaps.

It must be clear, however, that this review can provide only hypotheses between familial impacts of HIV/AIDS and potential inter-generational implications for HIV infection among orphans, and that rigorous (preferably longitudinal) research is required in order to determine causality. Given this understanding of the current research on HIV risk among orphan populations, future research is necessary to (a) confirm and clarify geographic, socioeconomic, and temporal patterns of health and social risks associated with orphanhood, including risk for HIV infection among orphaned children;

(b) examine the longitudinal and interactive processes by which familial HIV infection and parental AIDSdeath affects children; and (c) measure magnitude of disparities between AIDS-orphaned, other-orphaned and non-orphaned children.

Policy responses to initial evidence around HIV and other health and social vulnerabilities among AIDSorphaned children must strike a balance between supporting evidence-informed interventions alongside sensitivity to the social context that might exacerbate vulnerabilities for AIDS-orphaned children. It is essential that the policy response to the data does not lead to the categorisation of AIDS-orphaned children as a 'high risk group' for HIV or other sexually transmitted infections. The identification of such 'high risk' groups 
in the past (i.e. men who have sex with men (MSM) and sex workers) has been shown to further stigmatise already-stigmatised people, with members of these groups regarded as causative agents for HIV transmission and its negative socioeconomic aftermath throughout society (Young and Meyer 2005). There is extensive evidence that AIDSorphaned and AIDS-affected children are already exposed to stigma as a result of familial HIV infection (Strode and Barrett Grant 2001; Varrall and Sherr 2007; Cluver et al. 2008). This review suggests that stigma may itself be a mechanism by which vulnerable children are exposed to greater risk for HIV infection and other health and psychosocial problems, and so it is imperative that such stigma is not exacerbated by wellmeaning but flawed research or policy.

\section{References}

Albus, K.E.; Weist, M.D. and Perez-Smith, A.M. (2004) 'Associations Between Youth Risk Behavior and Exposure to Violence: Implications for the Provision of Mental Health Services in Urban Schools', Behavior Modification 28.4: 548-64

Atwine, B.; Cantor-Graae, E. and Bajunirwe, F. (2005) 'Psychological Distress among AIDS Orphans in Rural Uganda', Social Science and Medicine 61.3: 555-64

Bärnighausen, T.; Hosegood, V.; Timaeus, I.M. and Newell, M-L. (2007) 'The Socioeconomic Determinants of HIV Incidence: Evidence from a Longitudinal, Population-Based Study in Rural South Africa', AIDS 21 suppl. 7: S29-S38

Bauman, L.J.; Foster, G.; Silver, E.J.; Berman, R. and Gamble, I. (2006) 'Children Caring for their III Parents with HIV/AIDS', Vulnerable Children and Youth Studies 1.1: 56-70

Bhargava, A. (2005) 'AIDS Epidemic and the Psychological Well-Being and School Participation of Ethiopian Orphans', Psychology, Health and Medicine 10.3: 263-75

Birdthistle, I.J.; Floyd, S.; Machingura, A.; Mudziwapasi, N.; Gregson, S. and Glynn, J.R. (2008) 'From Affected to Infected? Orphanhood and HIV Risk among Female Adolescents in Urban Zimbabue', AIDS 22.6: 759-66

Boris, N.W.; Thurman, T.R.; Snider, L., Spencer, E. and Brown, L. (2006) 'Infants and Young Children Living in Youth-Headed Households in Rwanda: Implications of Emerging Data', Infant Mental Health Journal 27.6: 584-602
It is also important to note that 'children affected by AIDS' do not typically function as a social group or as a community with a shared identity, and consequently group-based interventions for AIDSorphaned children might not be appropriate. Rather, AIDS-affected and AIDS-orphaned children can be better understood as particularly vulnerable members of AIDS-affected families and communities (Rotheram-Borus et al. 1999). As such, structural interventions might be appropriate for framing policies and practices to improve the general functioning of families and communities within which AIDS-affected children reside.
Brandt, R. (2007) 'Does HIV Matter When You are Poor and How? The Impact of HIV/AIDS on the Psychological Adjustment of South African Mothers in the Era of HAART', unpublished PhD dissertation, University of Cape Town

Brown, L.K.; Danovsky, M.B.; Lourie, K.; DiClemente, R.J. and Ponton, L.E. (1997) 'Adolescents with Psychiatric Disorder and the Risk of HIV', Journal of the American Academy of Child and Adolescent Psychiatry 36.11: 1609-17

Campbell, E. (2003) 'Note on Alcohol Consumption and Sexual Behaviour of Youths in Botswana', African Sociological Review 7.1: 146-61

Campbell, P.; Handa, S.; Moroni, M.; Odongo, S. and Palermo, T. (2008). 'A Situation Analysis of Orphans in 11 Eastern and Southern African Countries', (draft paper), Nairobi: UNICEF ESARO (Eastern and Southern Africa Regional Office)

Case, A. and Ardington, C. (2005) The Impact of Parental Death on School Enrolment and Achievement: Longitudinal Evidence from South Africa, CSSR Working Paper 97, Cape Town: Centre for Social Science Research, University of Cape Town

Case, A.; Paxson, C. and Ableidinger, J. (2002) 'Orphans in Africa: Parental Death, Poverty, and School Enrollment', Demography 41.3: 483-508

Cluver, L. and Gardner, F. (2007) 'Risk and Protective Factors for Psychological Well-Being of Orphaned Children in Cape Town: a Qualitative Study of Children's Views', AIDS Care 19.3: 318-25

Cluver, L.; Gardner, F. and Operario, D. (2008) 'Effects of Stigma and Other Community Factors 
on the Mental Health of AIDS-Orphaned

Children', Journal of Adolescent Health 42.4: 410-17

Cluver, L.; Gardner, F. and Operario, D. (2007)

'Psychological Distress among AIDS-Orphaned

Children in Urban South Africa', Journal of Child

Psychology and Psychiatry 48.8: 755-63

Dahoma, M.; Salim, A.; Abdool, R.; Othman, A.A.; Makame, H.; Ali, A.S.; Abdalla, A.; Juma, S.; Yahya, B.; Shaka, S.H.; Sharif, M.; Seha, A.M.; Mussa, M.; Shauri, O.M.; Nganaga, L. and Kibuka, T. (2006) 'HIV and Substance Abuse: the Dual Epidemics Challenging Zanzibar', African Journal of Drug and Alcohol Studies 5.2: 129-38

Dawes, A. and Mushwana, M. (2007) 'Monitoring Child Abuse and Neglect', in A. Dawes, R. Bray and A. van der Merwe (eds), Monitoring Child Rights and Wellbeing. A South African Approach, Cape Town: HSRC Press

Dawes, A.; Long, W.; Alexander, L. and Ward, C. (2006) 'A Situation Analysis of Children Affected by Maltreatment and Violence in the Western Cape: Report for the Research Directorate Department of Social Services \& Poverty Alleviation: Provincial Government of the Western Cape'. Cape Town: Human Sciences Research Council

Deblinger, E.; Lippman, R. and Steer, R. (1996) 'Sexually Abused Children Suffering Posttraumatic Stress Symptoms: Initial Treatment Outcome Findings', Child Maltreatment 1: 310-21

Dunkle, K.; Jewkes, R.; Brown, H.C.; Gray, G.E.; Mclntyre, R.A. and Harlow, S.D. (2004) 'Transactional Sex among Women in Soweto, South Africa: Prevalence, Risk Factors and Association with HIV Infection', Social Science \& Medicine 59.8: 1581-92

Esposito, S.; Musetti, L.; Musetti, M.C.; Tornaghi, R.; Corbella, S.; Massironi, E.; Marchisio, P.; Guareschi, A. and Principi, N. (1999) 'Behavioral and Psychological Disorders in Uninfected Children Aged 6 to 11 Years Born to Human Immunodeficiency Virus-Seropositive Mothers', Journal of Developmental and Behavioral Pediatrics 20.6: 411-17

Ferreira, M.; Keikelame, M.J. and Mosaval, Y. (2001) Older Women as Carers to Children and Grandchildren Affected by AIDS: A Study Towards Supporting the Carers, University of Cape Town, Institute of Ageing in Africa

Fisher, J.; Bang, H. and Kapiga, S. (2007) 'The Association Between HIV Infection and Alcohol Use: A Systematic Review and Meta-Analysis of
African Studies', Sexually Transmitted Diseases 43.11: 856-63

Fleming, D.T. and Wasserheit, J.N. (1999) 'From Epidemiological Synergy to Public Health Policy and Practice: the Contribution of Other Sexually Transmitted Diseases to Sexual Transmission of HIV Infection', Sexually Transmitted Infections 75.1: 3-17

Forehand, R.; Armistead, L.; Mose, E.; Simon, P. and Clark, L. (1998) 'The Family Health Project: An Investigation of Children Whose Mothers are HIV Infected', Journal of Consulting and Clinical Psychology 66.3: 513-20

Giese, S.; Meintjies, H.; Croke, R. and Chamberlain, R. (2003) Health and Social Services to Address the Needs of Orphans and Other Vulnerable Children in the Context of HIV/AIDS in South Africa: Research Report and Recommendations, Cape Town: Children's Institute, University of Cape Town

Gregson, S.; Nyamukapa, C.; Garnett, G.P.; Wamba, M.; Lewis, J.J.C.; Mason, P.R.; Chandiwana, S.K. and Anderson, R.M. (2005) 'HIV Infection and Reproductive Health in Teenage Women Made Vulnerable by AIDS in Zimbabwe', AIDS Care 177: 785-94

Jewkes, R.; Levin, J. and Penn-Kekana, L.A. (2003) 'Gender Inequalities, Intimate Partner Violence and HIV Preventive Practices: Findings of a South African Cross-Sectional Study', Social Science and Medicine 56.1: 125-34

Jewkes, R.; Vundule, C.; Maforah, F. and Jordaan, E. (2001) 'Relationship Dynamics and Teenage Pregnancy in South Africa', Social Science \& Medicine 52.5: 733-44

Juma, M.; Askew, I. and Ferguson, A. (2007) Situation Analysis of the Sexual and Reproductive Health and HIV Risks and Prevention Needs of Older Orphaned and Vulnerable Children in Nyanza Province, Kenya, Nairobi: Department of Children's Services, Government of Kenya

Kissin, D.; Zapata, L.; Yorick, R.; Vinogradova, E.N.; Volkova, G.; Cherkassova, E.; Lynch, A.; Leigh, J.; Jamieson, D.; Marchbanks, P. and Hillis, S. (2007) 'HIV Seroprevalence in Street Youth, St Petersburg, Russia', AIDS 21.17: 2333-40

Lindsey, E.; Hirschfeld, M. and Tlou, S. (2003) 'Homebased Care in Botswana: Experiences of Older Women and Young Girls', Health Care for Women International 24.6: 486-521

Longfield, K.; Glick, A.; Waithaka, M. and Berman, J. (2004) 'Relationships Between Older Men and Younger Women: Implications for STIs/HIV in Kenya', Studies in Family Planning 35.2: 125-34 
Makame, V; Ani, C. and Grantham-McGregor, S. (2002) 'Psychological Well-Being of Orphans in Dar El-Salaam, Tanzania', Acta Paediatrica 91: 459-65

Manuel, P. (2002) Assessment of Orphans and their Caregivers' Psychological Well-Being in a Rural Community in Central Mozambique, London: Institute of Child Health

McGaw, L. and Wameyo, A. (2005) 'Violence Against Children Affected by HIV/AIDS: a Case Study of Uganda. United Nations Study on Violence Against Children', Nairobi: World Vision International

Mishra, V.; Arnold, F.; Otieno, F.; Cross, A. and Hong, R. (2005) Education and Nutritional Status of Orphans and Children of HIV-Infected Parents in Kenya, DHS Working Paper series 24, Washington DC: United States Agency for International Development (USAID)

Muula, A.; Misiri, H.; Munthali, L.; Kalengo, S.; Kachali, F.; Mbewe, M. and Msuku, S. (2003) 'The Living Situations of Orphans in Periurban Blantyre, Malawi', South African Medical Journal 93.12: 920-1

Nkosana, J. and Rosenthal, D. (2007) 'The Dynamics of Intergenerational Sexual Relationships: the Experience of Schoolgirls in Botswana', Sexual Health 4(3): 181-7

Nostlinger, C.; Bartoli, G.; Gordillo, V.; Roberfroid, D. and Colebunders, R. (2006) 'Children and Adolescents Living with HIV Positive Parents: Emotional and Behavioural Problems', Vulnerable Children and Youth Studies 1.1: 29

Nsutebu, E.F.; Walley, J.D.; Mataka, E. and Simon, C.F. (2001) 'Scaling-up HIV/AIDS and TB Homebased Care: Lessons from Zambia', Health Policy and Planning 16.3: 240-7

Nyamukapa, C.; Gregson, S.; Lopman, B.; Saito, S.; Watts, H.J.; Monasch, R. and Jukes, M.C.H. (2008) 'HIV-associated Orphanhood and Children's Psychosocial Distress: Theoretical Framework Tested with Data from Zimbabue', American Journal of Public Health 98.1: 133-41

Nyamukapa, C.A.; Gregson, S.; Lopman, B.; Saito, S.; Watts, H.J.; Monasch, R. and Jukes, M.C.H. (2006) HIV-associated Orphanhood and Children's Psychosocial Disorders: Theoretical Framework Tested with Data from Zimbabwe, Harare: Biomedical Research and Training Institute, London: Imperial College and Zimbabue: UNICEF

Oleke, C.; Blystad, A.; Fylkesnas, K. and Tumwine, J.K. (2007) 'Constraints to Educational Opportunities of Orphans: a Community-Based Study from Northern Uganda', AIDS Care 19.3: 361-8
Operario, D.; Pettifor, A.; Cluver, L.; MacPhail, C. and Rees, H.V. (2008) 'Parental Death During Schoolaged Years and Completion of Compulsory School Education among Young People in South Africa', Journal of Research on Adolescence 18.1: $173-86$

Operario, D.; Pettifor, A.; Cluver, L.; MacPhail, C. and Rees, H. (2007) 'Prevalence of Parental Death among Young People in South Africa and Risk for HIV Infection', Journal of Acquired Immune Deficiency Syndromes 44: 93-8

Palermo, T. and Peterman, A. (2008) 'Orphanhood as a Risk Factor for Child Marriage and Early Sexual Debut: Evidence from subSaharan Africa', JLICA Learning Group 4 (draft paper)

Parker, W.; Makhubele, B.; Ntlabati, P. and Connolly, C. (2007) Concurrent Sexual Partnerships among Young Adults in South Africa: Challenges for HIV Prevention Communication, Braamfontein: Centre for AIDS Development, Research and Evaluation (CADRE)

Pettifor, A.; Van der Straten, A.; Dunbar, M.S.; Shiboski, S.C. and Padian, N.S. (2004) 'Early Age of First Sex: a Risk Factor for HIV Infection among Women in Zimbabwe', AIDS 18.10: 1435-42

Pettifor, A.; Rees, H.; Kleinschmidt, l.; Steffenson, A.E.; MacPhail, C.; Hlongwa-Madikizda, L.; Vermaak, K. and Padian, N.S. (2003) 'Young People's Sexual Health in South Africa: HIV Prevalence and Sexual Behaviors from a Nationally Representative Household Survey', AIDS 19.14: 1525-34

Rochat, T.; Richter, L.; Doll, H.A.; Buthelezi, N.P.; Tomkins, A. and Stein, A. (2006) 'Depression among Pregnant Rural South African Women Undergoing HIV Testing', Journal of the American Medical Association 295.12: 1376-78

Rotheram-Borus, M.-J.; Lightfoot, M. and Shen H. (1999) 'Levels of Emotional Distress among Parents Living with AIDS and their Adolescent Children', AIDS and Behaviour 3.4: 367-72

Rowan, A. and Foy, D. (1993) 'Post-traumatic Stress Disorder in Child Sexual Abuse Survivors: $A$ Literature Review', Journal of Traumatic Stress 6.1: $3-20$

Royce, R.A.; Sena, A.; Cates, W. and Cohen, M.S. (1997) 'Sexual Transmission of HIV', New England Journal of Medicine 336.15: 1072-8

Steinberg, M.; Johnson, S.; Schierhout, G. and Ndegwaet D. (2002) A Survey of Households Impacted by HIV/AIDS in South Africa: What are the Priority Responses?, Menlo Park, California: Kaiser Family Foundation 
Strode, A. and Barrett Grant, K. (2001) The Role of Stigma and Discrimination in Increasing the Vulnerability of Children and Youth Infected with and Affected by HIV/AIDS, London: Save the Children (UK)

Su, P.Y.; Tao, F.B.; Sun, Y.; Huang, K.; Zhu, P. and Cheng, X.L. (2007) 'Psychological Well-Being among Adolescents of Parents Living with AIDS or HIV', Zhonghua Liu Xing Bing Xue Za Zhi 28.6: 562-6

Thurman, T.; Brown, L.; Richer, L.; Maharaj, P. and Magnani, R. (2006) 'Sexual Risk Behavior among South African Adolescents: Is Orphan Status a Factor?', AIDS and Behavior 10.6: 627-35

Varrall, R. and Sherr, L. (2007) 'When is a Child Called an AIDS Orphan? Confusion Over Definitions and Implications for Care', AIDS Impact Conference, Marseilles
Wild, L. (2001) 'The Psychosocial Adjustment of Children Orphaned by AIDS', Journal of Child and Adolescent Mental Health 13.1: 3-25

Wild, L.; Flisher, A.; Bhana, A. and Lombard, C. (2006) 'Psychosocial Adjustment of Adolescents Orphaned in the Context of HIV/AIDS', Poster presented at the International Society for the Study of Behavioural Development Biennial Meeting, Melbourne, Australia, July 2006

Wood, C.G.A.; Whittet, S. and Bradbeer, C.S. (1997) 'ABC of Palliative Care: HIV Infection and AIDS', British Medical Journal 315.7120: 1433-6

Young, R. and Meyer, I. (2005) 'The Trouble with 'MSM' and 'WSW': Erasure of the Sexual-Minority Person in Public Health Discourse', American Journal of Public Health 95.7: 1144-9 